\title{
Analysis of Centrifugal Compressor Testing Capabilities
}

\author{
Stojko Biočanin ${ }^{1 *}$, Milica Timotijević2 ${ }^{2}$ \\ ${ }^{1}$ Technical College of Professional Studies, Belgrade (Serbia) \\ "'Šinvoz" d.o.o, Zrenjanin (Serbia)
}

The work shows examining of the centrifugal compressor for which there are no technical conditions by which the compressor manufacturer defines the form and important characteristics of the measuring installation. In the absence of the necessary data, a table for testing of centrifugal compressors was designed, where the pipeline measures and other details are freely defined in accordance with the available possibilities.

\section{Keywords: Welding, Centrifugal compressor, Functional testing}

\section{INTRODUCTION}

The work showed an examining of the centrifuge compressor of a motor vehicle. The compressor lid had damages in the shape of cracks. The damaged lid was regenerated by welding. The mentioned procedure was necessary because there were no compressors nor their parts on the market. The lid is made of aluminum alloy. TIG procedure was used to weld the crack. There was no manufacturer's documentation for the compressor on the shape and characteristics of the measuring installation. Nevertheless, the compressor should have been examined for function after the welding procedure was carried out. For this reason, a table for functional testing of compressors was designed.

\section{DESCRIPTION OF THE SUBJECT OF THE WORK}

The centrifugal compressor (Figure 1) is used to increase air pressure entering the engine cylinders. It consists of a flowing part and a multiplier. The flow part consists of: rotor (7), diffuser (4), disc (5) and precompressor pipe (6). The body (19) and lid (3) are made of Aluminum alloy. In the body there are: gears of two-stage reduction, elastic and two frictional joints [3].

From the gears on the engine's collet shaft, the rotation is transferred to the gear block and further across the gears (24), small (34) and large (25) gears on the gear (33) of the rotor shaft. The gear block consists of: gear vein (22), vaudeville (21) and connected gear with it using a screw (18). In the gear block, an elastic coupling is placed. It consists of six packages, with two springs (17) with clamps (15 and 16). The packages are placed in a wreath and guide tray. The elastic coupling is designed to reduce the dynamic load of the compressor drive. The axle (20) of the block and the axle of the inter-cogs (24) are immobile, and their support is in the body and the lid.

The large gear (25) moves freely on a bronze nail, placed on the sleeve of the small gear. It contains a frictional compressor coupling, consisting of six weights (28) with a cap (27), a cleaner (30) and a spring (32). Weights are started, over caps and springs, with a attachment tightly connected to a small gear. Under the presence of centrifugal forces, weights settle on the conical surfaces of the large gear. When increasing and reducing rotations, weights slightly connect or separate the gear vein of a large gear, thus relieving the compressor drive from inertia loads.
The diffuser has 23 arrow shaped spatulas. The precompressor pipe disk is placed with a central air entrance into the compressor. In the opening of the pre-compressor pipe (6) is a cop (1) with a torque port (2), from where the air is taken through the pipe to create super pressure in exhaust compound compensators, for better sealing of the compensator's rings.

The rotor (7) of the compressor relies, over coasters, on a cocoon (13), and is tightened to the shaft (29) by the rolling (11) over coasters (12). Not to get oil into the air-passing area, they are placed in groove shells (13) of two rings (14), which perform sealing with a cocoon in the compressor lid.

Lubrication of the rotor shaft tray and the gear tray the is under pressure. The gears are oiled with oil that passes through the trays. The oil, which performed lubrication, flows into the engine carter.

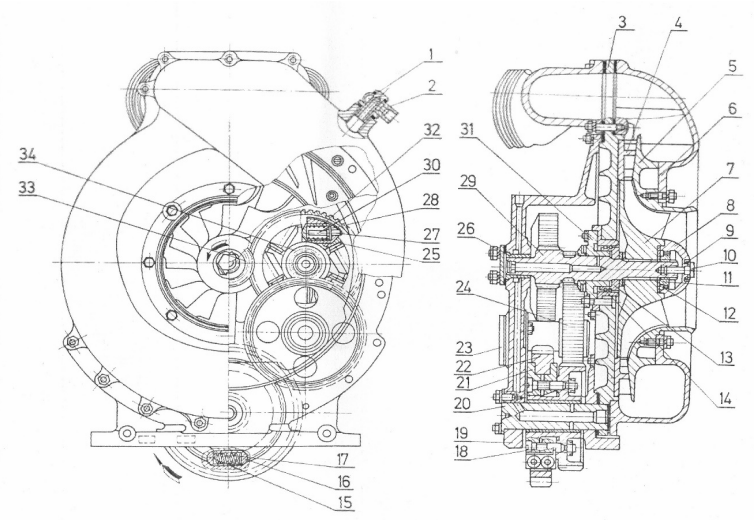

Figure 1: Centrifugal Compressor [1]

\section{WELDING OF CRACKS}

The compressor lid is made by casting under pressure from Al-alloy quality AlSi12.

During the general overhaul of the engine, damage of the compressor lid was found in the form of an irregularly shaped opening, dimensions of $30 \times 30 \mathrm{~mm}$ minimum to $70 \times 70 \mathrm{~mm}$ maximum (Figure 8). Lid damage is due to an improper handling and maintenance or hidden errors in the lid material was made of. The basic material of the lid is iron-cast under the pressure of AlSand12 quality. The chemical composition of the alloy is in Table 1 . 
Table 1: Chemical composition of the alloy [2]

\begin{tabular}{|c|c|c|c|c|c|c|c|c|c|c|}
\hline \multicolumn{3}{|c|}{ Required } & \multicolumn{7}{c|}{ Permitted impurities, \% } & Density, \\
\cline { 1 - 2 } & $\mathrm{Si}$ & $\mathrm{Al}$ & $\mathrm{Ni}$ & $\mathrm{Fe}$ & $\mathrm{Zn}$ & $\mathrm{Cu}$ & $\mathrm{Mg}$ & $\mathrm{Ti}$ & $\mathrm{Pb}$ & $\mathrm{kg} / \mathrm{dm}^{3}$ \\
\hline 0.1 & 11.2 & $\begin{array}{c}\text { complement } \\
\text { to } 100 \%\end{array}$ & 0.08 & 0.45 & 0.12 & 0.1 & 0.1 & 0.15 & 0.1 & 2.65 \\
\hline
\end{tabular}

Welding of aluminum and aluminum alloys is generally feasible to all conventional welding procedures. Bearing in mind the fact that it is individual production, welding of the lid with electrolyte procedure with nonmelting electrode in the protection of inert gas (Wolfram Inert Gas-TIG procedure) is accepted.

The thickness of the lid wall at the spot of the damage is $4 \mathrm{~mm}$. Al 99.5\%, $4 \mathrm{~mm}$ thick sheet was selected for the patch, because AlSand 12 sheet is not being produced. Choosing some other alloy would create additional problems of welding ability.

The characteristics and application of aluminum depend on its purity. Increasing impurities in Aluminum reduces corrosion resistance, electrical conductivity, and above all strength.

99.8\% or above pure Aluminum, is applied for the production of chemical equipment, which functions in very aggressive environments. A very important feature of Aluminum is to build $\mathrm{Al}_{2} \mathrm{O}_{2}$ oxide on its surface in the form of a $0,01 \mu \mathrm{m}$ layer. This layer occurs at higher temperatures and in conditions of increased humidity, and reaches thickness of $0,03 \mu \mathrm{m}$ to $0,1 \mu \mathrm{m}$. The layer has high density and prevents further Aluminum oxidation. Cast Aluminum alloys are applied for complex mechanical strains and often contain higher percentage presence of alloy elements.

Since the basic materials of different chemical composition (the lid is from AlSi12 and the patch of $\mathrm{Al}$ 99.5), as well as on the basis of recommendations for selecting additional materials, the accepted wire is $\mathrm{S}-\mathrm{AlSi}_{5}$, $\phi 0,3 \mathrm{~mm}$. [3]

With this quality of the wire, obtained seam had composition between Al 99,5 and AlSi12.

Protective gas was used from auxiliary (expendable) material. The protective gas was aimed at protecting basic and additional material while in melted state, as well as during the period after hardening as protection from the effects of oxidation, so as not to create undesirable oxides. Also, in addition to this basic role, the protective gas was partly to cool Wolfram's electrode.

When welding, argon and helium could be used as pure gases or gas mix: argon and helium, argon and hydrogen, argon and oxygen.

Due to the good supply of argon on the market as well as the lower purchase price than helium, argon was accepted as a protective gas of higher purity of $99.96 \%$. On the milling machine the edges of the opening are processed in order to obtain the regular geometric shapes (rectangle, square, circle...). After processing the lid opening, the sheet was made - patch. The junction of the patch and the lid is given in Figure 2.

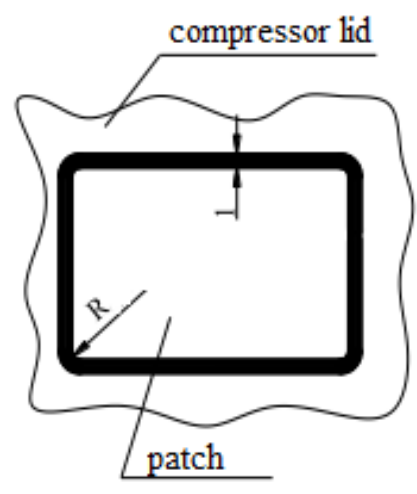

Figure 2: The patch and lid junction

For the sheet thickness of $4 \mathrm{~mm}$, according to table 6 it is accepted [3]:

- Two-sided "I" joint,

- Space between parts $\mathrm{s}=1 \mathrm{~mm}$,

- One weld on both sides.

Based on the recommended parameters for welding Aluminum and Aluminum alloys, the following welding parameters were [3]:

- $\quad$ Current power I = 180A,

- Number of cycles $\mathrm{i}=2$,

- Argon flow $\mathrm{Q}=9 l_{\min }$,

- Diameter of extra material $d_{z}=3 \mathrm{~mm}$.

Preheating of Aluminum is often performed when it is necessary to avoid the appearance of porousness in the metal seam.

Since the welded lid patch junction must ensure impenetrableness, the appearance of porousness in the metal seam is not permitted.

Due to the above, the overheating of the lid and the patch in the chamber furnace at a temperature of $150^{\circ} \mathrm{C}$ was applied.

Based on the data presented and after the preheating was performed, welding was performed in the following order (Figure 3):

- Patch joining in four places,

- Welding the patch by a welding plan, according to figure 3 , on the inside of the lid in one aisle,

- Welding the patch by a welding plan, according to figure 3 , on the outside of the lid in one aisle. 


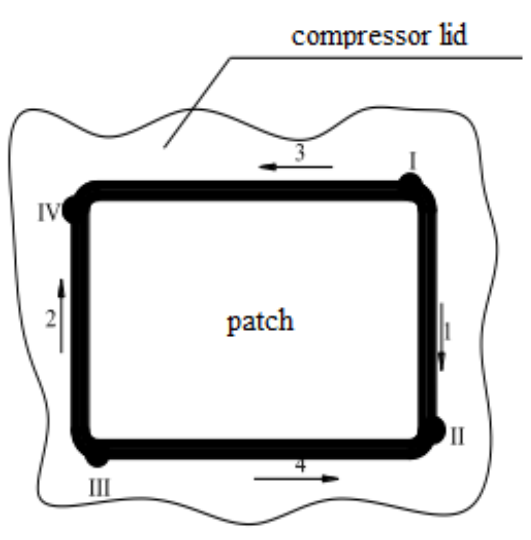

Figure 3: Welding plan

\section{COMPRESSOR TESTING}

After welding compressor lid regeneration carried out, a functional compressor test was performed. The initial problem was the lack of data on the basic characteristics of the measurement installation:

- Diameter and length of suction and thyme platoon,

- Exact locations and types of regulatory valves,

- Presence of expansion container for calming and slowing down of electricity on the thyme pipeline,

- Types and positions of temperature probes,

- Presence of laminators for air current regulation in front of measuring sites.

In the absence of the necessary data, a test table was designed to test centrifugal compressors (Figure 4). The installation is complemented by an oil preheating device, with a control thermometer.

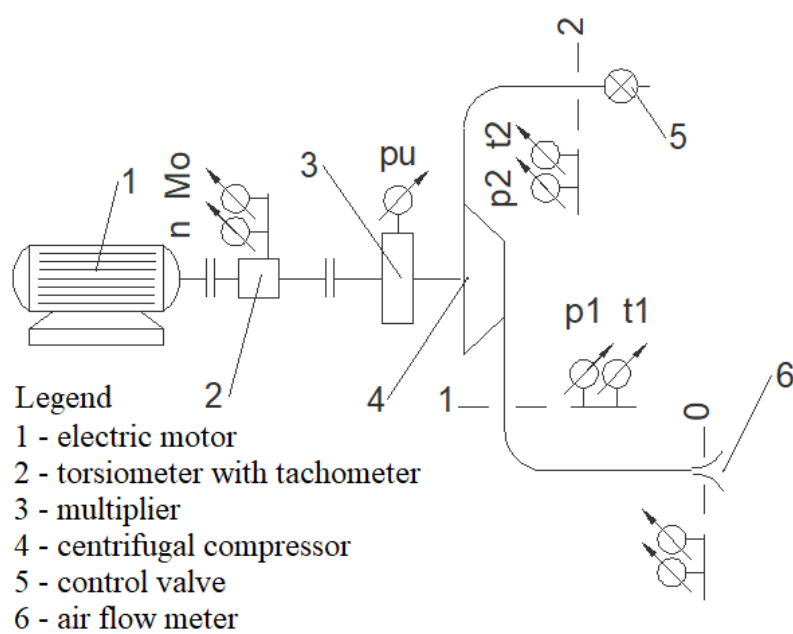

Figure 4: Test table for testing centrifugal compressor

Compressor quality is checked at work points corresponding to engine speed modes $n=1300 \mathrm{~min}^{-1}, n=1800 \mathrm{~min}^{-1}$ and $n=2000 \mathrm{~min}^{-1}$ at full power. The quality rating process is all about forming compressor characteristics at constant rev numbers, corresponding to the specified rev speeds. Characteristics are determined by four work points. The boundaries on the maximum flow line correspond to a fully open dampener valve [4,5]. The accuracy of the method increases as the number of points through which the curve forms increase.

Based on the relative position of reference points in relation to the recorded characteristics, a rating is given on whether the compressor meets the prescribed requirements.

The values of the control parameters that were taken from the Technical Conditions for compressor testing on handover, are in Table 2.

Table 2: Values of the control parameters [4]

\begin{tabular}{|c|c|c|c|c|}
\hline & $\Delta \mathrm{P}_{\text {ТОТ }}, \mathrm{kPa}$ & $\Delta \mathrm{T}_{\text {TOT, }} \mathrm{K}$ & $\mathrm{Pk}, \mathrm{kW}$ & $\mathrm{m}_{\mathrm{KOR}}, \mathrm{kg} / \mathrm{s}$ \\
\hline $\mathrm{n}=1300 \mathrm{~min}^{-1}$ & 32.35 & 38 & 0.7 & 27.96 \\
\hline $\mathrm{n}=1800 \mathrm{~min}^{-1}$ & 69.63 & 67 & 1.1 & 80.93 \\
\hline $\mathrm{n}=2000 \mathrm{~min}^{-1}$ & 88.24 & 82 & 1.3 & 117.72 \\
\hline
\end{tabular}

Technical conditions for handover compressor testing [4] define the correcting of mass air flow to standard conditions, $\left(T_{\text {ref }}=288,152 \mathrm{~K}\right.$ и $\left.p_{\text {ref }}=101,3 \mathrm{kPa}\right)$. Correction factor is calculated according to the form:

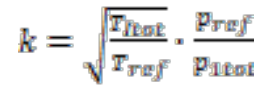

The bringing to normal atmospheric conditions is also predicted for differences in pressure values $\Delta p_{\text {tot }}$, and temperature values $\Delta T_{\text {tot }}$, as well as for the engaged strength P. Since the technical conditions for the handover compressor tests do not contain a correction procedure, these sizes are not being brought to normal.

The test table in the current configuration does not have an expansion container on the thyme pipeline, whose presence would allow for measurements of pressure and temperature in low-speed air currents. In such conditions, the measured pressure, i.e. temperature, would be approximately equal to total or static sizes $\left(P_{\text {mey }} \approx p_{\text {tot }} \approx p_{\text {stat }}, t j . t_{\text {mey }} \approx t_{\text {tot }} \approx t_{\text {stat }}\right)$. Since the reference sections on the installation occur at speeds of over $100 \mathrm{~m} / \mathrm{s}$, the calculation process of determining total and static sizes from measured pressure and temperature values has been applied. Since no probes were used to measure the stop temperature, an assumption was made as recommended by literature that standard probes register $50 \%$ dynamic temperature.

Table 3 presents the results of the examination. The table contains data on mass flow, air flow rates in reference sections, static and total sizes of the states in measuring sections 1 and 2 . The recommended values for the isentropic and actual current work, isentropic, total and mechanical level of usefulness, as well as the degree of increase in compressor pressure were also given. 
Also, the data are listed on engaged torque, propulsion engine power and pressure and temperature differences at front and back of the compressor. The sizes specified in the last sentence are used, along with data for mass flow, as reference control parameters, through which the quality of the tested compressor is checked.

Table 3: Results of the examination (First part of the Table 3)

\begin{tabular}{|c|c|c|c|c|c|c|c|c|c|}
\hline & \multicolumn{5}{|c|}{ Compressor NO 12AT5347 } & \multirow[b]{3}{*}{7} & \multirow[b]{3}{*}{8} & \multirow[b]{3}{*}{9} \\
\hline & & \multicolumn{5}{|c|}{ Testing results } & & & \\
\hline $\begin{array}{c}\text { Serial } \\
\text { number }\end{array}$ & 1 & 2 & 3 & 4 & 5 & 6 & & & \\
\hline$P_{w a}\left(\mathrm{~kg} / \mathrm{m}^{3}\right)$ & 1.21 & 1.21 & 1.21 & 1.21 & 1.21 & 1.21 & 1.21 & 1.21 & 1.21 \\
\hline$k$ & 1.02 & 1.03 & 1.04 & 1.04 & 1.03 & 1.03 & 1.05 & 1.05 & 1.06 \\
\hline$m_{L}(\mathrm{~kg} / \mathrm{s})$ & 0.51 & 0.86 & 1.09 & 0.98 & 0.83 & 0.65 & 1.16 & 1.30 & 1.42 \\
\hline$m_{\log }(k g / s)$ & 0.52 & 0.89 & 1.14 & 1.02 & 0.86 & 0.66 & 1.22 & 1.37 & 1.50 \\
\hline$p_{1}(\mathrm{~Pa})$ & -931.63 & -2471.28 & -3795.15 & -3167.55 & -2333.98 & -1421.96 & -4511.06 & -5442.69 & -6815.62 \\
\hline$p_{2}(P a)$ & 1461.23 & 2922.46 & 6641.96 & 20324.39 & 28294.73 & 32279.91 & 8900.22 & 10892.81 & 14612.30 \\
\hline$p_{\text {ias }}(\mathrm{pa})$ & 98068.37 & 96528.72 & 95204.83 & 95823.45 & 96666.02 & 97578.04 & 94488.94 & 93557.31 & 92184.38 \\
\hline$p_{\text {2asp }}(P a)$ & 100451.2 & 101922.5 & 105642.0 & 119324.4 & 127294.4 & 131279.9 & 107900.2 & 109892.8 & 113612.3 \\
\hline$T_{\mathrm{a} S}(\mathrm{~K})$ & 284.57 & 284.10 & 283.33 & 283.77 & 283.93 & 284.69 & 283.52 & 283.30 & 282.88 \\
\hline$c_{1}(\mathrm{~m} / \mathrm{s})$ & 24.17 & 40.96 & 52.83 & 47.12 & 39.83 & 30.67 & 56.70 & 63.98 & 70.53 \\
\hline$P_{w 1}\left(\mathrm{~kg} / \mathrm{m}^{\mathrm{s}}\right)$ & 1.20 & 1.18 & 1.17 & 1.18 & 1.19 & 1.19 & 1.16 & 1.15 & 1.14 \\
\hline$p_{\text {inor }}(P a)$ & 98419.09 & 97521.83 & 96838.55 & 97138.82 & 97606.80 & 98139.83 & 96355.19 & 95912.55 & 95008.29 \\
\hline$T_{\text {I }}[K]$ & 284.87 & 284.94 & 284.71 & 284.87 & 284.71 & 285.15 & 285.12 & 285.34 & 285.36 \\
\hline$T_{2 s}(K)$ & 292.41 & 301.36 & 312.84 & 315.40 & 317.34 & 319.36 & 318.25 & 328.10 & 339.85 \\
\hline$c_{2}(\mathrm{~m} / \mathrm{s})$ & 45.08 & 76.52 & 97.75 & 78.22 & 62.86 & 47.56 & 103.63 & 117.31 & 127.85 \\
\hline$p_{U I}\left(\mathrm{~kg} / \mathrm{m}^{\mathrm{N}}\right)$ & 1.20 & 1.18 & 1.18 & 1.32 & 1.40 & 1.43 & 1.18 & 1.17 & 1.16 \\
\hline$p_{2 \text { arar }}(P a)$ & 101677.7 & 105372.2 & 111263.2 & 123356.6 & 130055.7 & 132899.6 & 114243.3 & 117922.3 & $\begin{array}{c}1231.30 \\
7\end{array}$ \\
\hline$D_{p_{\text {and }}}(\mathrm{Pa})$ & 3258.6 & 7850.4 & 14424.7 & 26217.7 & 32448.9 & 34759.8 & 17888.2 & 22009.8 & 28122.4 \\
\hline$D T_{\text {家 }}(K)$ & 8.6 & 19.3 & 32.9 & 33.6 & 34.6 & 35.3 & 38.5 & 49.6 & 62.6 \\
\hline$T_{\text {2tar }}(K)$ & 293.43 & 304.28 & 317.60 & 318.44 & 319.30 & 320.48 & 323.59 & 334.94 & 347.99 \\
\hline$\pi_{\mathrm{RES}}$ & 1.02 & 1.06 & 1.11 & 1.25 & 1.32 & 1.35 & 1.14 & 1.17 & 1.23 \\
\hline$\pi_{\text {III }}$ & 1.03 & 1.08 & 1.15 & 127 & 1.33 & 1.35 & 1.19 & 1.23 & 1.30 \\
\hline$Y i k(g / k g)$ & 2674.30 & 6393.03 & 11546.80 & 20179.63 & 24409.23 & 25900.75 & 14240.18 & 17366.33 & 21946.84 \\
\hline$h\left(j / k_{g}\right)$ & 8599.55 & 19428.00 & 33033.80 & 33723.35 & 34746.60 & 35490.19 & 38648.53 & 49832.56 & 62915.79 \\
\hline$\eta_{\text {ax }}$ & 0.31 & 0.33 & 0.35 & 0.60 & 0.70 & 0.73 & 0.37 & 0.35 & 0.35 \\
\hline$P s(W)$ & 1371.49 & 5478.05 & 12620.28 & 19772.08 & 20378.17 & 16765.88 & 16566.47 & 22592.90 & 31056.66 \\
\hline$P k(W)$ & 4876.4 & 19575.3 & 39996.2 & 36325.7 & 31850.7 & 25829.8 & 47987.8 & 70591.6 & 96132.7 \\
\hline$\eta_{h x}$ & 0.28 & 0.28 & .32 & 0.54 & 0.64 & 0.65 & 0.35 & 0.32 & 0.32 \\
\hline$\eta_{\text {m }}$ & 0.90 & 0.85 & 0.90 & 0.91 & 0.91 & 0.89 & 0.94 & 0.92 & 0.93 \\
\hline$n_{1}\left(\right.$ min $\left.^{-1}\right)$ & 7958.01 & 13396.65 & 17435.64 & 17448.97 & 17475.63 & 17488.96 & 18795.30 & 21394.65 & 23994.00 \\
\hline
\end{tabular}

(Second part of the Table 3)

\begin{tabular}{|c|c|c|c|c|c|c|c|c|}
\hline & \multicolumn{5}{|c|}{ Compressor NO 12AT5347 } & \multirow[b]{3}{*}{16} & \multirow[b]{3}{*}{17} \\
\hline & & \multicolumn{5}{|c|}{ Testing results } & & \\
\hline $\begin{array}{c}\text { Serial } \\
\text { number }\end{array}$ & 10 & 11 & 12 & 13 & 14 & 15 & & \\
\hline$p_{w a}\left(\mathrm{~kg} / \mathrm{m}^{\mathrm{s}}\right)$ & 1.21 & 1.21 & 1.20 & 1.20 & 1.20 & 1.20 & 1.20 & 1.20 \\
\hline$k$ & 1.06 & 1.05 & 1.04 & 1.07 & 1.07 & 1.07 & 1.06 & 1.05 \\
\hline $\mathrm{m}_{\mathrm{L}}(\mathrm{kg} / \mathrm{s})$ & 1.37 & 1.16 & 0.96 & 1.46 & 1.47 & 1.44 & 1.32 & 1.15 \\
\hline 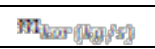 & 1.145 & 1.22 & 0.99 & 1.56 & 1.57 & 1.53 & 1.39 & 1.21 \\
\hline$p_{1}(\mathrm{~Pa})$ & -6942.00 & -4756.23 & -2991.03 & -7404.02 & -7502.09 & -7207.89 & -6129.16 & -4756.23 \\
\hline$p_{2}(\mathrm{~Pa})$ & 34006.81 & 59511.93 & 65356.85 & 16472.05 & 37859.15 & 56456.63 & 74788.42 & 81696.06 \\
\hline$P_{\text {ans }}(P a)$ & 92508.00 & 94243.77 & 96008.97 & 91596.0 & 91497.91 & 91792.11 & 92870.84 & 94243.77 \\
\hline$p_{\text {2asp }}(\mathrm{Pa}]$ & 133006.8 & 158511.9 & 164356.8 & 115472.1 & 136859.1 & 155456.6 & 173788.4 & 180696.1 \\
\hline$T_{1 \mathrm{si}}(K)$ & 283.16 & 284.21 & 285.19 & 283.67 & 283.65 & 284.12 & 284.65 & 285.62 \\
\hline$c_{1}(\mathrm{~m} / \mathrm{s})$ & 68.26 & 56.95 & 46.11 & 73.58 & 74.23 & 72.17 & 65.49 & 56.71 \\
\hline$P_{u 1}\left(\mathrm{~kg} / \mathrm{m}^{\mathrm{s}}\right)$ & 1.14 & 1.16 & 1.17 & 1.12 & 1.12 & 1.13 & 1.14 & 1.15 \\
\hline $\begin{array}{c}\text { Serial } \\
\text { number }\end{array}$ & 10 & 11 & 12 & 13 & 14 & 15 & 16 & 17 \\
\hline
\end{tabular}




\begin{tabular}{|c|c|c|c|c|c|c|c|c|}
\hline$P_{\text {and }}(P a)$ & 95159.44 & 96117.51 & 97255.92 & 94641.0 & 94594.07 & 94723.23 & 95308.60 & 96092.28 \\
\hline$T_{\text {西r }}(K)$ & 285.48 & 285.83 & 286.25 & 286.37 & 286.39 & 286.72 & 286.79 & 287.22 \\
\hline$T_{\mathrm{c}_{\mathrm{s}}}\left(\mathrm{K}^{2}\right)$ & 343.47 & 347.54 & 351.07 & 348.11 & 385.53 & 361.79 & 363.50 & 366.88 \\
\hline$c_{2}(\mathrm{~m} / \mathrm{s})$ & 107.88 & 77.00 & 61.66 & 133.18 & 116.64 & 100.90 & 83.11 & 70.65 \\
\hline$P_{\omega d}\left(\mathrm{~kg} / \mathrm{m}^{2}\right)$ & 1.35 & 1.59 & 1.63 & 1.16 & 1.33 & 1.50 & 1.67 & 1.72 \\
\hline$p_{\text {zan }}(P a)$ & 140741.3 & 163222.4 & 167456.3 & 125720.9 & 145906.2 & 163076.9 & 179540.6 & 184978.6 \\
\hline$D_{p_{\text {zarar }}}(\mathrm{Pa})$ & 45581.9 & 67104.8 & 70201.4 & 31079.9 & 51312.1 & 68353.6 & 84232.0 & 88885.8 \\
\hline$D T_{\text {口ar }}(K)$ & 63.7 & 64.7 & 66.7 & 70.6 & 78.9 & 80.1 & 80.2 & 82.1 \\
\hline$T_{\text {2ar }}(K)$ & 349.17 & 350.50 & 352.97 & 356.93 & 365.31 & 366.85 & 366.94 & 369.36 \\
\hline$\pi_{\text {Res }}$ & 1.44 & 1.68 & 1.71 & 1.26 & 1.50 & 1.69 & 1.87 & 1.92 \\
\hline$\pi_{\text {Rr }}$ & 1.48 & 1.70 & 1.72 & 1.33 & 1.54 & 1.72 & 1.88 & 1.93 \\
\hline$Y i k(j / k g)$ & 33792.06 & 46768.76 & 48206.69 & 24199.33 & 37740.67 & 48144.56 & 56928.79 & 59207.40 \\
\hline$h(j / k g)$ & 63984.96 & 64963.70 & 67021.86 & 70889.09 & 79275.27 & 80503.59 & 80517.67 & 82517.09 \\
\hline Daxe & 0.53 & 0.72 & 0.72 & 0.34 & 0.48 & 0.60 & 0.71 & 0.72 \\
\hline$P s(W)$ & 46393.82 & 54380.85 & 46073.47 & 35396.30 & 55637.52 & 69110.44 & 74892.90 & 68210.21 \\
\hline$P k(W)$ & 93305.3 & 80676.1 & 69144.9 & 109547.3 & 123878.2 & 120098.9 & 111700.4 & 99732.5 \\
\hline$\eta_{\text {nof }}$ & 0.50 & 0.67 & 0.67 & 0.32 & 0.45 & 0.58 & 0.67 & 0.68 \\
\hline$\eta_{\text {m }}$ & 0.94 & 0.94 & 0.93 & 0.95 & 0.94 & 0.96 & 0.95 & 0.95 \\
\hline$n_{1}\left(\min ^{-1}\right)$ & 23994.00 & 2399400 & 24113.97 & 25353.66 & 26726.65 & 26726.65 & 26726.65 & 26726.65 \\
\hline
\end{tabular}

\section{TESTING RESULTS}

Table 4 has a comparative overview of referenced and measured sizes. Measured sizes are displayed at two points. These points on the top and down side limit the area. which contain reference sizes.

Table 4: Comparative overview of referenced and measured sizes

\begin{tabular}{|c|c|c|c|c|c|c|c|c|c|}
\hline & & \multicolumn{2}{|c|}{$\Delta \mathrm{P}_{\text {2тот. }} \mathrm{kPa}$} & \multicolumn{2}{|c|}{$\Delta \mathrm{T}_{\text {тот. }} \mathrm{K}$} & \multicolumn{2}{|c|}{ Pk. kW } & \multicolumn{2}{|c|}{$\mathrm{m}_{\mathrm{KOR}} \cdot \mathrm{kg} / \mathrm{s}$} \\
\hline \multirow{2}{*}{$\begin{array}{l}1300 \\
\min ^{-1}\end{array}$} & Ref. & \multicolumn{2}{|c|}{32.35} & \multicolumn{2}{|c|}{38.00} & & 7.96 & \multicolumn{2}{|c|}{0.70} \\
\hline & Meas. & 32.45 & 34.76 & 35.17 & 36.21 & 32.85 & 25.83 & 0.84 & 0.64 \\
\hline \multirow{2}{*}{$\begin{array}{c}1800 \\
\min ^{-1}\end{array}$} & Ref. & \multicolumn{2}{|c|}{69.53} & \multicolumn{2}{|c|}{67.00} & \multicolumn{2}{|c|}{80.93} & \multicolumn{2}{|c|}{1.10} \\
\hline & Meas. & 67.10 & 70.20 & 66.35 & 68.20 & 80.68 & 69.14 & 1.20 & 0.97 \\
\hline \multirow{2}{*}{$\begin{array}{l}2000 \\
\min ^{-1}\end{array}$} & Ref. & \multicolumn{2}{|c|}{88.24} & \multicolumn{2}{|c|}{82.00} & \multicolumn{2}{|c|}{117.2} & \multicolumn{2}{|c|}{1.3} \\
\hline & Meas. & 84.23 & 88.89 & 81.62 & 83.10 & 111.70 & 99.73 & 1.46 & 1.18 \\
\hline
\end{tabular}

In addition to the above-mentioned test results, the following was noted:

- There's no oil leak registered on the body and lid of the multiplier,

- There are no oil marks on the compressor wheel shovels,

- No excessive heating of the base in the zones of deposited shells of multipliers,

- No increased noise levels have been registered in the compressor.

\section{CONCLUSION}

The results of the test unequivocally indicate that an adequate process of welding the compressor cover was chosen. Based on the results of the test, it can be noted that the compressor meets the prescribed requests in terms of achieving the reference characteristics. This means that the test compressor can, as correct and reliable, be used on a motor vehicle.

\section{REFERENCES}

[1] Compressor description and operation TU -I. Technical repair institute - Čačak (1982)
[2] T. Lipinski "Mechanical properties of alsi12 alloy with aluminium bronze", University of Warmia and Mazury in Olsztyn. Engineering for rural development, Poland (2017)

[3] B.Delić. „Tungsten electrode welding - TIG“. DUZS Belgrade (1987)

[4] "Technical requirements for handover tests of compressors". SS-55-5MP (1986)

[5] Compressor maintenance TU - II.- Technical repair institute - Čačak (1982)

\section{Analiza mogućnosti ispitivanja centrifugalnog kompresora}

Stojko Biočanin ${ }^{1 *}$, , Milica Timotijević ${ }^{2}$

${ }^{1}$ Visoka tehnička škola strukovnih studija, Beograd (Srbija)

2"Šinvoz" d.o.o., Zrenjanin (Srbija)

$U$ radu je prikazano ispitivanje centrifugalnog kompresora za koje ne postoje tehnički uslovi kojima 
proizvođač kompresora definiše oblik i bitne karakteristike merne instalacije. $U$ nedostatku potrebnih podataka, projektovana je tabela za ispitivanje centrifugalnih kompresora, gde su mere cevovoda $i$ ostali detalji slobodno definisani $u$ skladu sa raspoloživim mogućnostima.

Ključne reči: Zavarivanje, Centrifugalni kompresor, Funkcionalno ispitivanje 